Archive for

Organic Chemistry

Arkivoc 2018, part iv, 132-138

\title{
A highly chemo-, regio-, and stereoselective metallacycle-mediated annulation between a conjugated enyne and an ene-diyne
}

\author{
Zachary A. Shalit and Glenn C. Micalizio* \\ Department of Chemistry, Burke Laboratory, Dartmouth College, Hanover, NH 03755 \\ Email: glenn.c.micalizio@dartmouth.edu
}

In honor our friend and colleague, Professor Gordon Gribble

Received 01-19-2018

Accepted 03-01-2018

Published on line 03-28-2018

\section{Abstract}

Alkoxide-directed metal-centered intermolecular [2+2+2] annulation is shown to chemo-, regio-, and stereoselectively engage two polyunsaturated substrates in productive cyclization chemistry. This annulation process is unique in the field, revealing that it is possible to selectively engage three of five $\pi$-systems residing in the coupling partners in initial $[2+2+2]$ reaction, and demonstrating that one of the two remaining $\pi$ systems (the TMS-alkyne) can ultimately serve to simply generate a new metallacyclopentene of great potential value in additional metallacycle-mediated coupling chemistry.
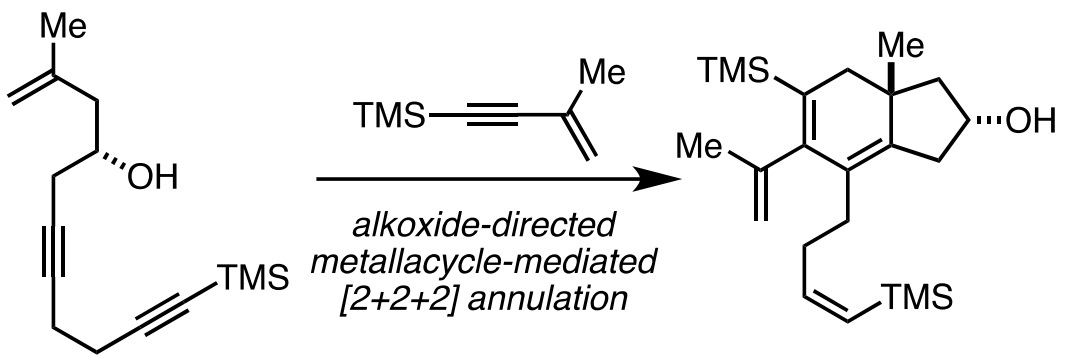

Keywords: Metallacycle-mediated cross-coupling, titanium, chemoselective, directed C-C bond-formation, tandem reaction. 


\section{Introduction}

Since the pioneering work of Professor Vollhardt that revealed the great value of metal-centered $[2+2+2]$ annulation chemistry for accessing stereodefined carbo- and heterocyclic targets, this area of organometallic chemistry has grown to occupy a unique role in organic synthesis (Figure 1A)..$^{1-5}$ These reactions that may be considered to be inspired by the foundation of chemistry first established by Reppe, ${ }^{6}$ and later developed by luminaries in the field, often embrace organometallic intermediates of relevance for $[2+2+2]$ annulation as a means to realize a large swathe of complex and diverse bond-forming reactions. ${ }^{7-13}$ While many of these advances have been demonstrated to be of great value in complex molecule or natural product synthesis, ${ }^{14}$ it is typically the case that intermolecular versions of this type of organometallic chemistry are rather restricted in scope, and therefore of limited value in stereoselective synthesis, including natural product synthesis. ${ }^{14}$ As illustrated in Figure 1B, controlling intermolecular reactivity in metallacycle-mediated coupling chemistry is challenging due to the possibility of generating products of varied composition, in addition to the clear issues of selectivity that surface when employing: (a) unsymmetrical systems (regioselectivity), (b) alkenes as one of the three reactive $\pi$-systems ( $\pi$-facial selectivity), and/or (c) polyunsaturated substrates where issues of chemoselectivity surface.

A. Vollhardt: Examples of Cobalt-mediated $[2+2+2]$ annulation chemistry in carbocycle synthesis. featuring an intramolecular $[2+2+2]$

(1)

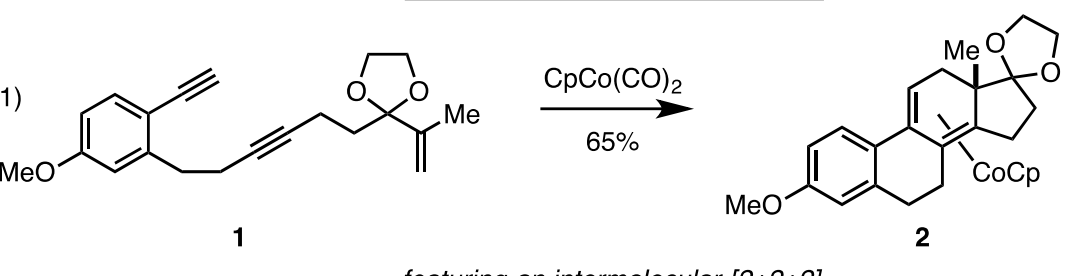

featuring an intermolecular $[2+2+2]$

(2)

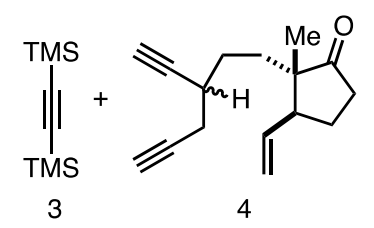

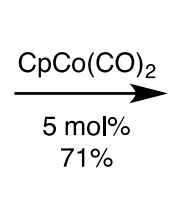

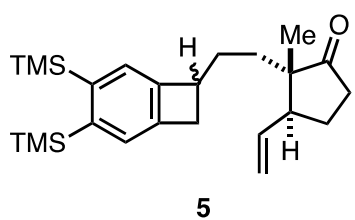

B. Challenges of intermolecular $[2+2+2]$ annulation: Product composition:

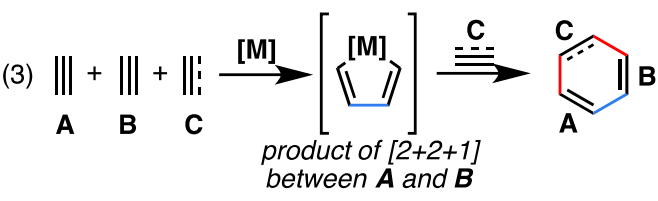

other possible products have varied compositions:

- homotrimers $=\boldsymbol{A}-\boldsymbol{A}-\boldsymbol{A} ; \boldsymbol{B}-\boldsymbol{B}-\boldsymbol{B} ; \boldsymbol{C}-\boldsymbol{C}-\boldsymbol{C}$

- products containing a homodimer motif $=$ $A-A-B ; A-A-C ; B-B-A ; B-B-C ; C-C-A ; C-C-B$

Regioselectivity with unsymmetric systems? Stereoselectivity (simple and relative stereoselection)?

Figure 1. Introduction to metal-centered $[2+2+2]$ annulation chemistry.

For over ten years, we have been interested in establishing principles that ultimately result in avoiding the common dependence on intramolecularity and/or use of symmetrical substrates in this rather broad area of chemistry. To date, we have reported over thirty distinct and highly selective coupling reactions between a variety of unsymmetrically substituted unsaturated systems, and have demonstrated the utility of these reactions in total synthesis and function-oriented synthesis ${ }^{15}$ of representative members of diverse families of natural products (alkaloids, terpenoids, and polyketides). ${ }^{16-27}$ These reactions, termed metallacycle-mediated cross-coupling processes, have recently grown to include [2+2+2] annulation reactions between alkynes and 1,6- and 1,7-enynes as a means to prepare angularly substituted hydrindanes and decalins (Figure 2A). ${ }^{28-32}$ Here, in efforts that aimed to explore the question of whether it is possible to chemoselectively engage two polyunsaturated substrates in metallacycle-mediated annulative cross-coupling, we have elucidated the first organometallic transformation of its kind, where four of five resident $\pi$-unsaturations in the overall reaction are embraced as sites of reactivity in a highly selective annulation reaction (Figure 2B). 


\section{Results and Discussion}

A. Metallacycle-mediated cross-coupling for angularly substituted hydrindanes and decalins.

(4)

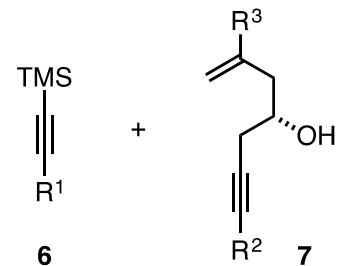

(5)

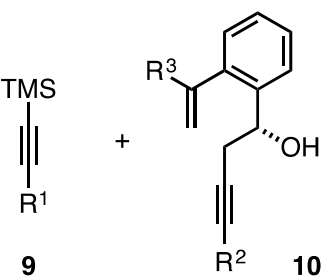

TMS-alkyne

$\mathrm{Ti}(\mathrm{O} i-\mathrm{Pr})_{4}, c-\mathrm{C}_{5} \mathrm{H}_{9} \mathrm{MgCl}$

(or $n$-BuLi)

then alkoxide of enyne

$\mathrm{PhMe}$, or $\mathrm{Et}_{2} \mathrm{O}$

TMS-alkyne

$\mathrm{Ti}(\mathrm{O} i-\mathrm{Pr})_{4}, c-\mathrm{C}_{5} \mathrm{H}_{9} \mathrm{MgCl}$ (or $n$-BuLi)

then alkoxide of enyne $\mathrm{PhMe}$, or $\mathrm{Et}_{2} \mathrm{O}$ quench with $\mathrm{PhCHO}$ or

1,6-heptadiene<smiles>[R]C1=C([R5])C[C@@]2([R3])C[C@@H](O)CC2=C([R])C1</smiles><smiles>[R]C1=C(S(C)(=O)=O)CC2([R3])C([R1])=C([R])c3ccccc3[C@@H]2C1</smiles>

11
B. Coupling of an enyne to an ene-diyne: Achieving selectivity by embracing reactivity of 3 of the $5 \pi$-systems in $[2+2+2]$.

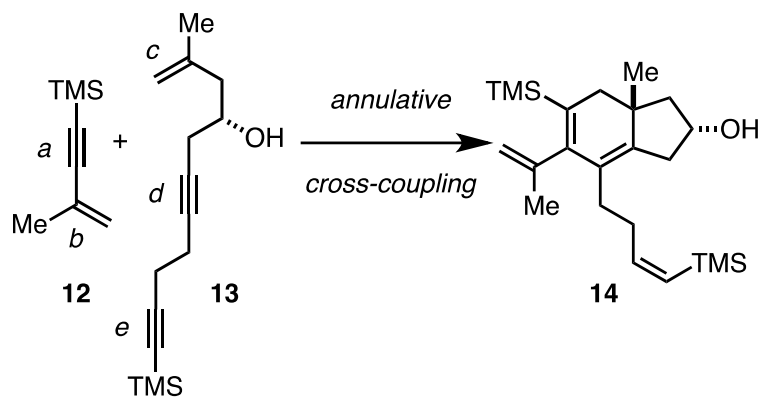

selective engagement of $\pi$-systems " $a$ ", " $c$ ", and " $d$ "

in regio- and stereoselective

intermolecular $[2+2+2]$, with net reduction of alkyne " $e$ "

Figure 2. Alkoxide-directed metallacycle-mediated annulative cross-coupling and selective engagement of a subset of $\pi$-systems resident in polyunsaturated substrates.

To explore the coupling reaction depicted in Figure 2B, efforts were first directed toward the synthesis of the desired ene-diyne 13. As illustrated in Figure 3A, epichlorohydrin was easily advanced to the desired enediyne 13 by initial reaction with isopropenylmagnesium bromide and Cul, followed by treatment with base to generate the low molecular weight alkenyl epoxide $16 .{ }^{33}$ With this intermediate in hand, regioselective opening of the epoxide with the Li-acetylide of diyne 17 , promoted by the action of $\mathrm{BF}_{3} \bullet \mathrm{OEt}_{2}$, delivered the desired coupling partner 13 in 66\% yield.

Ti-mediated annulation was then pursued as depicted in Figure 3B. Initial chemoselective activation of the commercially available enyne $\mathbf{1 2}$ by the action of $\mathrm{Ti}(\mathrm{O} i-\mathrm{Pr})_{4}$ and $n-\mathrm{BuLi}$, followed by addition of the lithium alkoxide of ene-diyne $\mathbf{1 3}$ as a solution in $\mathrm{PhMe}$, and quenching of the reaction with aqueous $\mathrm{NaHCO}_{3}$, resulted in the formation of the cross-conjugated triene-containing hydrindane 14, isolated in $51 \%$ yield as a single regio- and stereoisomer - no evidence was found for the formation of any other isomer of this coupled product, nor was evidence found for the presence of the TMS-alkyne containing product $15 .^{32}$

As depicted in Figure 3C, a mechanistic rationale for the formation of $\mathbf{1 4}$ is based on initial alkoxidedirected reaction between the preformed Ti-alkyne complex of $\mathbf{1 2}$ (I) with the internal alkyne of ene-diyne $\mathbf{1 3}$ that is proximal to the hydroxy group. The resulting fully substituted metallacyclopentadiene (III) can then participate in stereoselective intramolecular [4+2] to deliver the bridged bicyclic metallacyclopentene intermediate IV. We currently believe that this intermediate serves as the source of Ti for ligand transfer to the third reactive alkyne of this substrate combination (the TMS-alkyne of the ene-diyne coupling partner 13), resulting in the intermediacy of a new titanacyclopropene intermediate (VI). Interestingly, this intermediate organometallic does not appear competent to engage the 1,1-disubstituted alkene in carbometalation chemistry en route to the generation of a new carbocyclic system ( VI $\rightarrow$ VII $\rightarrow \mathbf{1 5}$ ). ${ }^{34}$ Rather, aqueous quenching of this reaction delivers the tricycylic product $\mathbf{1 4}$ that contains a pendent (Z)-vinylsilane. 
A. Synthesis of the ene-diyne coupling partner 13.
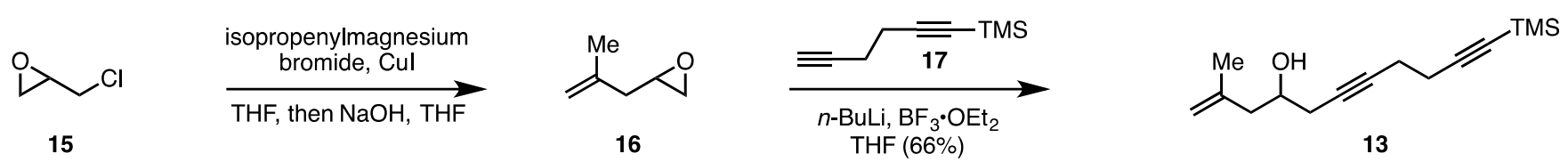

B. Coupling of enyne 12 with ene-diyne $\mathbf{1 3}$ deliver a reduced product of annulation.
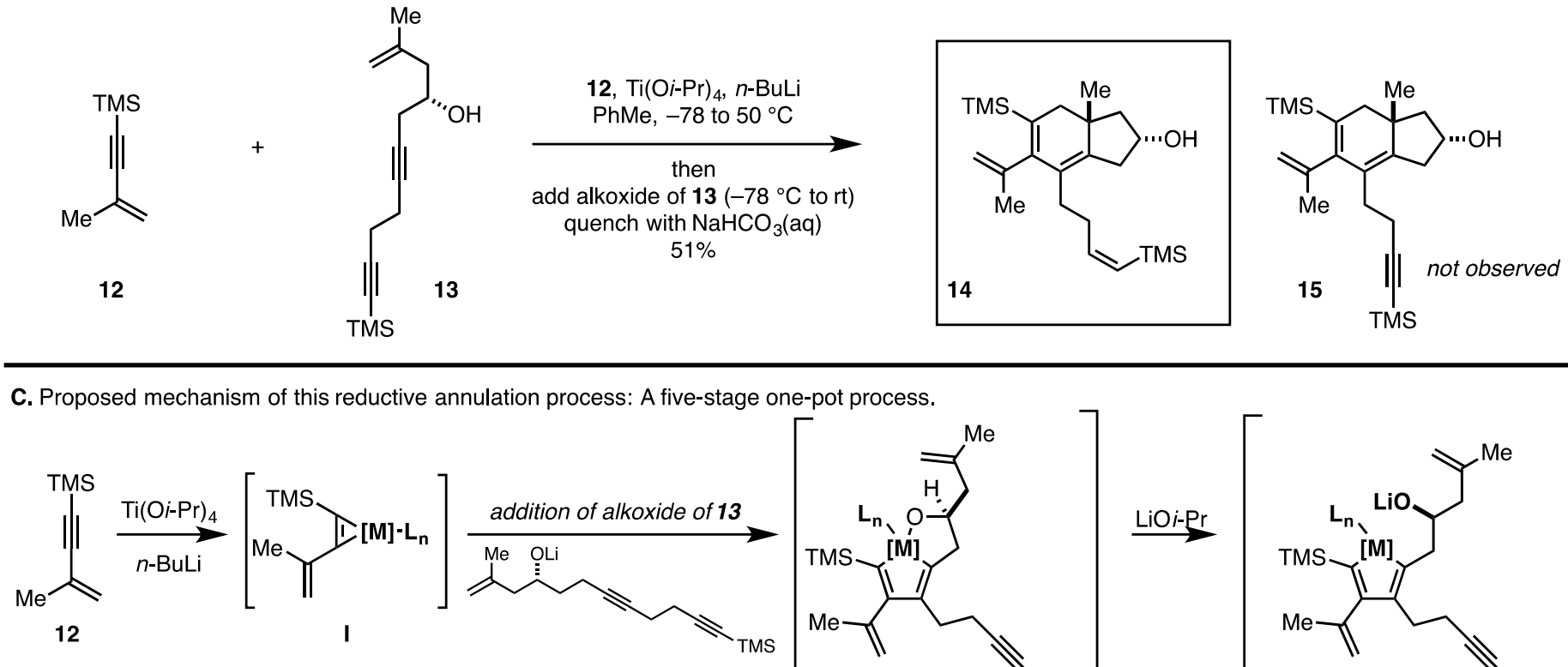

stage 1 selective alkyne activation stage 2
alkoxide-directed regio- and chemoselective carbometalation

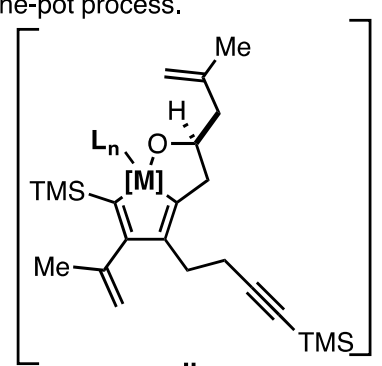

II

stage 3 ligand exchange and stereoselective [4+2]<smiles>C=C(C)C1=C(C(=O)NCC(=O)O)CC(C)(C)C[C@H](O)C1</smiles>

14

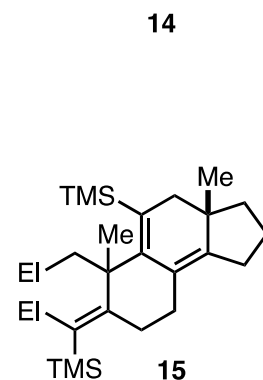
stage 5 aqueous quench

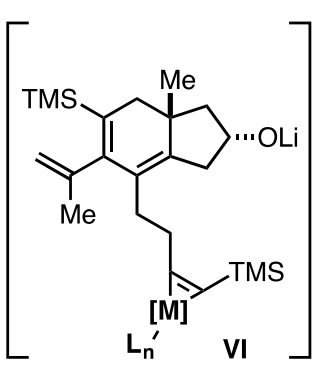<smiles>[101InH]</smiles>

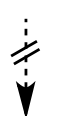

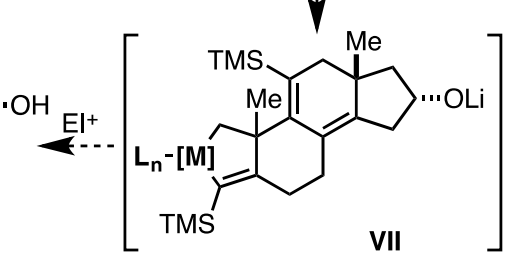

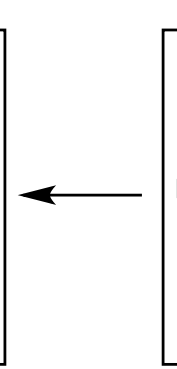

L

$$
\text { (achent }
$$
igand exchange: metallacyclopentene-to-metallacyclopropene

stage 4
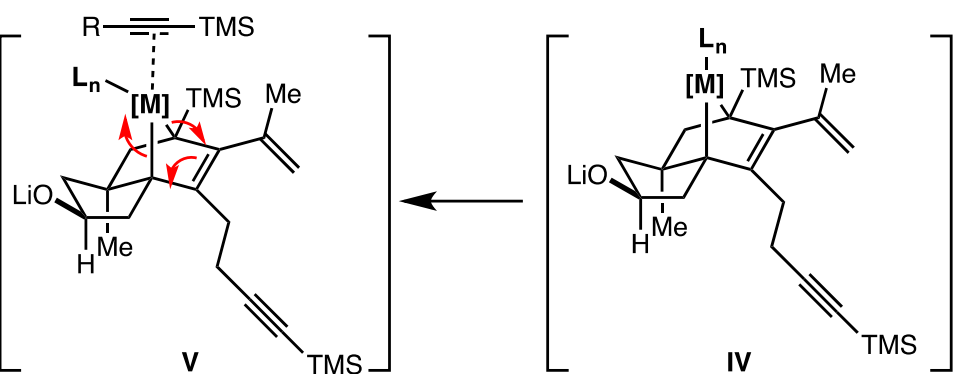<smiles>C=C(C)CC(O)Cc1[nH]c(CCCCC)c(CCC#CC(C)C)c1C(=C)C</smiles>

[4+2]

Figure 3. Synthesis of ene-diyne 13, and exploration in metallacycle-mediated annulative cross-coupling.

\section{Conclusions}

A unique and highly selective intermolecular [2+2+2] annulation reaction of polyunsaturated substrates has been described. The reaction is believed to be possible due to the power of alkoxide-direction as a force 
to control the regio- and stereochemical course of metallacycle-mediated coupling reactions. Observations made in the course of this study have led to the hypothesis that a pendent alkyne on the enyne substrate has the potential to engage the bridged bicyclic organometallic intermediate generated in the course of [2+2+2] annulation in a simple ligand exchange reaction, and defines a unique sequence of chemical transformations of potential value in more complex multi-component coupling chemistry. We look forward to exploring the value of this new sequence for addressing challenging problems associated with the synthesis of terpenoid and terpenoid-inspired targets.

\section{Experimental Section}

Synthesis of (3R,4R)-4-((tert-butyldimethylsilyl)oxy)-4-(furan-2-yl-3-methylbutan-1-ol (14). To a solution of 2methyl-4-trimethylsilyl-1-butene $(12,1.288 \mathrm{~mL}, 7.24 \mathrm{mmol})$ in anhydrous toluene $(45 \mathrm{~mL})$ was added Ti(O-i$\mathrm{Pr})_{4}(2.145 \mathrm{~mL}, 7.24 \mathrm{mmol})$ at $\mathrm{rt}$. The mixture was cooled to $-78{ }^{\circ} \mathrm{C}$ and $n$-BuLi $(2.46 \mathrm{M}$ in hexanes, $5.87 \mathrm{~mL}$, $14.46 \mathrm{mmol}$ ) was added dropwise via syringe. The reaction flask was removed from the cooling bath and the mixture was warmed to $\mathrm{rt}$ before heating to $50{ }^{\circ} \mathrm{C}$ (without a reflux condenser) for $1 \mathrm{~h}$. After this period, the reaction solution was cooled to $r$ and then placed in $a-78{ }^{\circ} \mathrm{C}$ cooling bath.

Simultaneously, ene-diyne $13(0.600 \mathrm{~g}, 2.41 \mathrm{mmol})$ was dissolved in anhydrous toluene $(15 \mathrm{~mL})$ and treated with $n$-BuLi $(2.46 \mathrm{M}$ in hexanes, $0.981 \mathrm{~mL}, 2.41 \mathrm{mmol})$ at $-78^{\circ} \mathrm{C}$. The reaction mixture was stirred at $-78^{\circ} \mathrm{C}$ for 15 minutes, and then warmed to rt over 5 minutes. The alkoxide solution was added dropwise, via cannula, to the Ti-alkyne complex and then gradually warmed to $\mathrm{rt}$ overnight (13 $\mathrm{h}$ ). The reaction mixture was quenched with saturated aq $\mathrm{NaHCO}_{3}(40 \mathrm{~mL})$, and the organic and aqueous phases were separated. The aqueous layer was extracted with EtOAc $(\times 3)$, and the combined organic phases were dried over anhydrous $\mathrm{MgSO}_{4}$. The supernatant was removed from the drying agent by vacuum filtration through a glass fritted funnel, and the solvents were removed in vacuo to afford the crude product, which was purified by flash column chromatography with 89:11 hexanes-EtOAc to afford 14 (475 mg, 51\%) as a clear, colorless, amorphous solid.

Analytical Data for 14. TLC $\left(\mathrm{SiO}_{2}\right) \mathrm{R}_{f}=0.30$ (hexanes-ethyl acetate, 87:13); ${ }^{1} \mathrm{H} \mathrm{NMR}\left(600 \mathrm{MHz}, \mathrm{CDCl}_{3}\right) \delta 6.26$ $(\mathrm{dt}, J=14.0,7.0 \mathrm{~Hz}, 1 \mathrm{H}), 5.46(\mathrm{~d}, J 14.2 \mathrm{~Hz}, 1 \mathrm{H}), 4.99$ (app s, 1H), 4.80 (br s, 1H), 4.48 (app quintet, J $6.9 \mathrm{~Hz}$, 1H), $2.83(\mathrm{dd}, J 17.7,7.4 \mathrm{~Hz}, 1 \mathrm{H}), 2.36(\mathrm{dd}, J 17.7,6.3 \mathrm{~Hz}, 1 \mathrm{H}), 2.22(\mathrm{~d}, J 15.4 \mathrm{~Hz}, 1 \mathrm{H}), 2.17-2.02(\mathrm{~m}, 5 \mathrm{H}), 2.01$ (d, J $15.4 \mathrm{~Hz}, 1 \mathrm{H}), 1.77$ (br s, 3H), 1.50 (dd, J 12.3, $7.8 \mathrm{~Hz}, 1 \mathrm{H}), 0.84(\mathrm{~s}, 3 \mathrm{H}), 0.10(\mathrm{~s}, 9 \mathrm{H}), 0.09(\mathrm{~s}, 9 \mathrm{H}) ;{ }^{13} \mathrm{C} \mathrm{NMR}$ $\left(150 \mathrm{MHz}_{1} \mathrm{CDCl}_{3}\right) \delta 149.9,149.2,146.2,145.3,129.1,128.5,128.0,115.8,72.2,51.1,40.7,39.6,38.8,33.7$, 29.8, 24.6, 21.0, 0.4; IR (neat) 3315, 2953, 2924, 1606, 1246, 850, $836 \mathrm{~cm}^{-1}$; HRMS (ES-TOF) $\mathrm{m} / \mathrm{z}$ [M + H]: calcd for $\mathrm{C}_{23} \mathrm{H}_{41} \mathrm{OSi}_{2}$ 389.2696; found 389.2701.

\section{Acknowledgements}

The authors gratefully acknowledge financial support of this work by the NIH (NIGMS R01: GM080266). ZAS acknowledges Dr. Kang Du and Mr. Wan Shin Kim for early experimental guidance in the pursuit of this science. 


\section{Supplementary Material}

Supplemental material includes ${ }^{1} \mathrm{H}$ and ${ }^{13} \mathrm{C}$ NMR spectra for all new compounds.

\section{References}

1. Funk, R. L.; Vollhardt, K. P. C. J. Am. Chem. Soc. 1977, 99, 5483-5484. https://doi.org/10.1021/ja00458a044

2. Funk, R. L.; Vollhardt, K. P. C. J. Am. Chem. Soc. 1979, 101, 215-217. https://doi.org/10.1021/ja00495a035

3. Funk, R. L.; Vollhardt, K. P. C. J. Am. Chem. Soc. 1980, 102, 5253-5261. https://doi.org/10.1021/ja00536a023

4. Clinet, J. C.; Dunach, E.; Vollhardt, K. P. C. J. Am. Chem. Soc. 1983, 105, 6710-6712. https://doi.org/10.1021/ja00360a027

5. Vollhardt, K. P. C. Pure Appl. Chem. 1985, 57, 1819-1826. https://doi.org/10.1351/pac198557121819

6. Reppe, W.; Schweckendick, W. J. Justus Liebigs Ann. Chem. 1948, 560, 104-116. https://doi.org/10.1002/jlac.19485600104

7. Micalizio, G. C. Early Transition Metal Mediated Reductive Coupling Reactions. In: Comprehensive Organic Synthesis, $2^{\text {nd }}$ edition, 2014, Vol. 5, Oxford: Elsevier; pp. 1660-1737.

https://doi.org/10.1016/B978-0-08-097742-3.00535-8

8. Reichard, H. A.; Micalizio, G. C. Chem. Sci. 2011, 2, 573-589. https://doi.org/10.1039/COSC00394H

9. Reichard, H. A.; McLaughlin, M.; Chen, M. Z.; Micalizio, G. C. Eur. J. Org. Chem. 2010, 391-409. https://doi.org/10.1002/ejoc.200901094

10. Montgomery, J. Angew. Chem. Int. Ed. 2004, 43, 3890-3908.

11. Ng, S.-S.; Ho, C.-Y.; Schleicher, K. D.; Jamison, T. F. Pure Appl. Chem. 2008, 80, 929-939. https://doi.org/10.1351/pac200880050929

12. Skucas, E.; Ngai, M.-Y.; Komanduri, V.; Krische, M. J. Acc. Chem. Res. 2007, 40, 1394-1401. https://doi.org/10.1021/ar7001123

13. Negishi, E.; Takahashi Bull. Chem. Soc. Jpn. 1998, 71, 755-769. https://doi.org/10.1246/bcsj.71.755

14. O’Rourke, N. F.; Kier, M. J.; Micalizio, G. C. Tetrahedron 2016, 72, 7093-7123. https://doi.org/10.1016/i.tet.2016.08.053

15. Wender, P. A. Nat. Prod. Rep. 2014, 31, 433-440. https://doi.org/10.1039/C4NP00013G

16. Cheng, X.; Micalizio, G. C. J. Am. Chem. Soc. 2016, 138, 1150-1153. https://doi.org/10.1021/jacs.5b12694

17. Micalizio, G. C.; Hale, S. Acc. Chem. Res. 2015, 48, 663-673 https://doi.org/10.1021/ar500408e

18. Canterbury, D. P.; Scott, K. E. N.; Kubo, O.; Jansen, R.; Cleveland, J. L.; Micalizio, G. C. ACS Med. Chem. Lett. 2013, 4, 1244-1248. 
19. Jeso, V.; Iqbal, S.; Hernandez, P.; Cameron, M. D.; Park, H.; LoGrasso, P. V.; Micalizio, G. C. Angew. Chem. Int. Ed. 2013, 52, 4800-4804.

https://doi.org/10.1002/anie.201301323

20. Jeso, V.; Yang, C.; Cameron M. D.; Cleveland, J. L.; Micalizio, G. C. ACS. Chem. Biol. 2013, 8, 1241-1252. https://doi.org/10.1021/cb300582s

21. Yang, D.; Micalizio, G. C. J. Am. Chem. Soc. 2012, 134, 15237-15240. https://doi.org/10.1021/ja306362m

22. Diez, P. S.; Micalizio, G. C. Angew. Chem. Int. Ed. 2012, 51, 5152-5156. https://doi.org/10.1002/anie.201200035

23. Jeso, V.; Micalizio, G. C. J. Am. Chem. Soc. 2010, 132, 11422-11424. https://doi.org/10.1021/ja104782u

24. Yang, D.; Micalizio, G. C. J. Am. Chem. Soc. 2009, 131, 17548-17549. https://doi.org/10.1021/ja908504z

25. Macklin, T. K.; Micalizio, G. C. J. Am. Chem. Soc. 2009, 131, 1392-1393. https://doi.org/10.1021/ja809491b

26. Reichard, H. A.; Rieger, J. C.; Micalizio, G. C. Angew. Chem. Int. Ed. 2008, 47, 7837-7840. https://doi.org/10.1002/anie.200803031

27. Belardi, J. K.; Micalizio, G. C. Angew. Chem. Int. Ed. 2008, 47, 4005-4008. https://doi.org/10.1002/anie.200800400

28. Mizoguchi, H.; Micalizio, G. C. Angew. Chem. Int. Ed. 2016, 55, 13099-13103. https://doi.org/10.1002/anie.201606962

29. Mizoguchi, H.; Micalizio, G. C. J. Am. Chem. Soc. 2015, 137, 6624-6628. https://doi.org/10.1021/jacs.5b02107

30. Cheng, X.; Micalizio, G. C. Org. Lett. 2014, 16, 5144-5147. https://doi.org/10.1021/ol502496d

31. Jeso, V.; Aquino, C.; Cheng, X.; Mizoguchi, H.; Nakashige, M.; Micalizio, G. C. J. Am. Chem. Soc. 2014, 136, 8209-8212. https://doi.org/10.1021/ja504374j

32. Greszler, S. N.; Reichard, H. A.; Micalizio, G. C. J. Am. Chem. Soc. 2012, 134, 2766-2774. https://doi.org/10.1021/ja2105043

33. Dai, M.; Krauss, I. J.; Danishefsky, S. J. J. Org. Chem. 2008, 73, 9576-9583. https://doi.org/10.1021/jo8016814

34. Urabe, H.; Hideura, D.; Sato, F. Org. Lett. 2000, 2, 381-383. https://doi.org/10.1021/ol9904038 